\title{
Cobrança do uso da água e comportamento dos usuários industriais na bacia hidrográfica do Piracicaba, Capivari e Jundiaí
}

\author{
Jacques Demajorovic \\ Centro Universitário da FEl / Programa de Pós-Graduação em Administração \\ São Paulo / SP - Brasil
}

Carla Caruso

Universidade de São Paulo / Programa de Pós-Graduação em Educação

São Paulo / SP - Brasil

Pedro Roberto Jacobi

Universidade de São Paulo / Instituto de Energia e Ambiente, Programa de Pós-Graduação em Ciência Ambiental

São Paulo / SP - Brasil

\begin{abstract}
Esta pesquisa tem como objetivo avaliar como a cobrança do uso da água nas bacias do PCJ tem influenciado o comportamento dos usuários industriais no sentido de adotar estratégias para a racionalização do consumo de recursos hídricos. A metodologia inclui entrevistas em profundidade com múltiplos stakeholders, incluindo representantes das indústrias, do setor público, do Comitê de Bacia PCJ e organizações não governamentais. As conclusões apontam para um processo de implantação da cobrança pelo uso da água de baixa eficiência, ainda que resulte no estímulo do uso racional da água no setor. O principal fator é o preço reduzido da cobrança que não estimula as mudanças em profundidade na Gestão de Recursos Hídricos, além de gerar recursos financeiros pouco significativos para a preservação da qualidade da água na região.
\end{abstract}

Palavras-chave: cobrança pelo uso da água; indústria; instrumentos econômicos.

Pago por uso del agua y el comportamiento de los usuarios industriales en la cuenca de Paraíba, Capivari e Jundiaí

Esta investigación tiene como objetivo evaluar cómo el pago por uso de agua ha influido en el comportamiento de los usuarios industriales en la cuenca del PCJ. La metodología incluye entrevistas con múltiples partes interesadas, como representantes de la industria, el sector público, el Comité de Cuenca

DOI: http://dx.doi.org/10.1590/0034-7612137792

Artigo recebido em 16 jul. 2014 e aceito em 15 maio 2015. 
del PCJ y organizaciones no gubernamentales. Los resultados evidencian un proceso de baja eficiencia, aunque fueran identificados estímulos para la utilización racional del agua en la industria. El principal factor es el precio reducido del pago que no estimula cambios en profundidad en la Gestión de Recursos Hídricos y genera escasos recursos financieros para la preservación de la calidad del agua de la región.

Palabras clave: pago por uso de água; indústria; instrumentos económicos.

The impact of the water charging on the industrial users' behavior in Paraíba, Capivari and Jundiaí river basin

This article discusses the impact of the water charge in PCJ Basin on the industrial sector behavior, regarding the implementation of practices of water rationalization in the productive process. The methodological procedure included in-depth interviews with multiple stakeholders, including representatives of industry, public sector, river basin's committee and non-governmental organizations. Findings show a low efficiency on the implementation process of the water charge, even if it results on encouragement of the rational use of water in the sector. The main factor is the reduced price of the water charge that does not encourage deep changes in the management of water resources. Besides that, the water charge generates negligible financial resources towards the investments needs for preservation of the water quality in the region.

KEYWORDs: use of water charge; industry; economic instruments.

\section{Introdução}

O crescimento populacional, associado ao desenvolvimento acelerado da sociedade urbano-industrial, impacta a disponibilidade e a qualidade dos recursos hídricos. Embora o setor agropecuário seja identificado em diversos países como principal usuário de recursos hídricos, inclusive no Brasil, o setor industrial contribui para esse quadro. A produção em larga escala de bens demanda volumes crescentes de água e gera efluentes que, quando não tratados, impactam a qualidade dos recursos hídricos. Nesse contexto, cresce a importância da aplicação de instrumentos de gestão ambiental que induzam à modificação do comportamento dos diversos usuários de recursos hídricos de forma a racionalizar o consumo deste recurso natural (Brasileiro, Sinisgalli e Cichoski, 2010; Seroa da Motta, 2006). Duas estratégias podem ser utilizadas para a garantia da qualidade ambiental. Na maioria dos países, os instrumentos de comando e controle permanecem como ferramenta essencial de gestão ambiental por parte do setor público de forma a mitigar os impactos socioambientais. Eles implicam a imposição de normas para o acesso e uso de recursos naturais, tais como padrões de emissão, licenças e controle do uso do solo e da água. No entanto, as políticas de comando e controle não são necessariamente os mecanismos de gestão ambiental mais eficazes. Muitas vezes padronizam as tecnologias a serem utilizadas, não estimulando o processo de inovação das empresas para a melhoria de seu desempenho ambiental. Nesse contexto, a política ambiental em diversos países ampliou o uso de instrumentos econômicos que procuram empregar sinais de mercado, incluindo taxas ou subsídios, para reduzir o uso ineficiente desses recursos (Guimaraes, 
Demajorovic e Oliveira, 1995). O principal argumento em favor das taxas seria que, quando refletissem efetivamente os custos ambientais do uso de recursos hídricos, elas proveriam os usuários com incentivos efetivos para investimentos em inovação e tecnologias para redução de impacto ambiental (Glachant, 2002; Mejías, Lenihan e O’Reagan, 2009). Dessa forma, busca-se promover maior flexibilidade aos usuários de recursos hídricos para melhorar seu desempenho ambiental (Varela, 2008; Sinisgalli et al., 2009). Adicionalmente, Glachant (2002) defende o potencial do uso do instrumento em gerar recursos adicionais ao poder público para investimentos destinados à qualidade da água e sua preservação na própria região onde são arrecadados.

Importante destacar que os instrumentos econômicos não são substitutos dos tradicionais instrumentos de comando e controle. Veettil e colaboradores (2011) destacam a complementaridade dos instrumentos, como essencial para a gestão eficaz dos recursos hídricos em países desenvolvidos e em desenvolvimento. No Brasil, a gestão de recursos hídricos conta com uma série de instrumentos que combinam os tradicionais de comando e controle e os incentivos de mercado. A Lei Federal no 9.433/1997, que determinou a criação da Política Nacional de Recursos Hídricos e posteriormente do Sistema Nacional de Gerenciamento de Recursos Hídricos, definiu a cobrança do uso da água como um de seus instrumentos (Borges, 2008). Pizaia, Machado e Jungles (2002) defendem que a cobrança é fundamental para incentivar a redução de consumo dos usuários na realidade brasileira, uma vez que a fiscalização e a punição se mostram pouco efetivas para promover um uso mais racional dos recursos hídricos. As bacias dos rios Piracicaba, Capivari e Jundiaí (PCJ), onde a cobrança federal foi instituída em 2006 e a paulista em 2007, são consideradas uma referência nessa temática. Trata-se de uma região com graves problemas de disponibilidade de água em função da expansão urbana, agrícola e industrial e pelo fato de parcela significativa dos recursos hídricos ser revertida para o abastecimento da Região Metropolitana de São Paulo. Embora o setor agropecuário seja o principal consumidor de recursos hídricos no Brasil, esta pesquisa foca o setor industrial. Diversas razões justificam essa escolha. Na região estudada, os usuários industriais são o segundo maior consumidor de água, ficando atrás apenas das atividades de abastecimento (Barbi, 2007; Comitês PCJ, 2009). Destaca-se que a média de consumo de água da indústria no PCJ é acima da média nacional, que é de 14\%. Logo, a racionalização de seu uso nos processos industriais tem um papel importante na sustentabilidade hídrica da região. Em segundo lugar, preenche uma importante lacuna teórica, pois poucos são os estudos focados na questão de como a adoção desse instrumento tem induzido a mudanças no comportamento do usuário industrial. Por fim, observa-se no país um importante processo de desconcentração industrial, não apenas para o interior do estado de São Paulo, mas também para outras regiões do Brasil. Dessa forma, os novos polos industriais trazem novos desafios aos gestores públicos locais que necessitam aprimorar os instrumentos de gestão referentes à preservação ambiental, incluindo o esgotamento de recursos hídricos. Nesse contexto, este artigo tem como principal objetivo avaliar o impacto da cobrança do uso da água no comportamento dos usuários industriais do PCJ a partir da percepção dos múltiplos stakeholders envolvidos na gestão de recursos hídricos na região. 


\section{Os instrumentos de gestão dos recursos hídricos}

A Lei no 9.433/1997, que regulamenta a gestão brasileira de recursos hídricos, inclui os seguintes instrumentos: plano de recursos hídricos; enquadramento de corpos d'água; outorga de direito de uso; cobrança pelo uso da água; e sistema integrado de informação. Bafoni e Telles (2010:3) defendem que "os instrumentos de gestão devem atuar de forma sincronizada para garantir a maior efetividade da Política Nacional de Gerenciamento de Recursos Hídricos".

Para Souza Jr. (2009), os instrumentos definem-se a partir do sistema de informações, por ordem de hierarquia e utilização. O processo implica inicialmente a elaboração de um cadastro de usuários dos recursos hídricos, seguido pela implementação de um sistema de acesso público, que contemple as diversas necessidades de informação para gestão das águas.

A seguir, tem-se a revisão do enquadramento dos corpos d'água. Tal trabalho consiste em associar os rios às suas respectivas classes de uso, determinadas pela legislação ambiental. Esse reenquadramento é crucial na atualidade, pois define os objetivos de qualidade dos corpos d'água versus o tipo de uso dos recursos hídricos pelos usuários, influenciando no desenvolvimento dos Planos de Recursos Hídricos (Porto, 2003; Borges, 2008).

Os Planos de Recursos Hídricos são construídos com base nas negociações nos comitês de recursos hídricos de cada bacia, constituídos por representantes dos municípios, dos órgãos de estado e da sociedade civil organizada. Devem conter, entre outros temas, diagnóstico com disponibilidades hídricas, balanço entre as disponibilidades hídricas e as demandas atuais e futuras, metas de racionalização de uso das águas e programas de investimentos (Omura e Mazochi, 2010; Comitês PCJ, 2011). A outorga, por sua vez, caracteriza-se como um direito à utilização da água e permite um controle quantitativo e qualitativo dos recursos hídricos em uma determinada localidade (Borges, 2008:29). Em teoria, esse instrumento dota o poder público, a partir de seu cadastro de consumidores, de informações mais precisas em relação ao total de água consumida na localidade e podendo assim compará-la com a disponibilidade dos recursos.

A cobrança pelo uso da água fecha o ciclo dos instrumentos. De acordo com a Agência Nacional de Água (ANA) (2010a), a cobrança é um estímulo ao uso racional da água, em função das condições de escassez em quantidade e/ou em qualidade, já que a água deixou de ser um bem livre e passou a ter valor econômico. Braga (2008:24) destaca como um dos principais avanços nesse processo a inclusão dos conceitos de poluidor-pagador e usuário pagador, viabilizando a cobrança pelo consumo desse recurso natural. No primeiro caso, o consumidor paga pelos efeitos adversos causados sobre a qualidade de água, enquanto no segundo caso cobra-se do usuário por estar se apropriando por parcela de um recurso considerado público. Assim, a água deixou de ser um bem livre e passou a ter valor econômico (Ramos, 2007; Oliveira, 2003). Com relação aos recursos arrecadados com esse instrumento, é obrigatório que eles retornem à bacia de origem por meio de investimentos definidos nos planos de bacia aprovados pelos comitês de recursos hídricos. Para Martinez e Lahoz (2007) e Igam (2006), o modelo de cobrança estimulou o interesse de participação dos múltiplos stakeholders nos comitês de forma a influenciar em suas deliberações. 
A França foi a precursora para o mundo neste sistema a partir da década de 1970, onde a cobrança pelo uso da água atua em conformidade com a gestão da bacia hidrográfica (Barraqué, 1998). A cobrança é gerenciada por seis organismos de bacia e sua receita é carimbada para investimentos em sistemas de tratamento de água. Para Glachant (2002:28), o valor da cobrança decorre de um "jogo institucional", destacando-se um intenso processo de negociação entre os três principais atores envolvidos: Ministério do Meio Ambiente, Ministério de Finanças e municipalidades. Mediante o estudo do sistema francês com as devidas adaptações, a água ganhou valor econômico no contexto brasileiro (Ramos, 2007). A Lei no 9.433/1997 introduziu a cobrança pelo uso da água no Brasil no Sistema Integrado de Gerenciamento de Recursos Hídricos (SIGRH) instituído por meio da Lei no 7.663/1991 obedecendo a um dispositivo Constitucional (Ana, 2010). De forma análoga ao sistema francês, ainda em 1997, o Brasil designou a bacia hidrográfica como unidade de planejamento e gestão. O estado de São Paulo criou 22 Unidades de Gerenciamento de Recursos Hídricos (UGRHIs) em 1994, a partir da aprovação da lei estadual. O primeiro Comitê de Bacia Hidrográfica (CBH) a atuar na região e no Brasil foi o dos rios Piracicaba, Capivari e Jundiaí (PCJ), instalado no ano anterior à aprovação da Lei no 9.304. Jacobi e Barbi (2007) defendem que o modelo adotado no PCJ serviu como referência para os demais comitês que surgiram posteriormente. Além disso, os autores destacam a implementação da cobrança do uso da água como um dos principais avanços decorrentes da atuação do PCJ, sendo um de seus indicadores mais expressivos a adimplência de $97 \%$ dos usuários.

\section{A cobrança pelo uso da água no $\mathrm{PCJ}$}

Com aproximadamente 5 milhões de habitantes, a região da Bacia PCJ é considerada uma das mais importantes do Brasil, devido ao seu desenvolvimento econômico, representando cerca de 7\% do Produto Interno Bruto nacional (Ramos, 2007). A região do PCJ experimentou um forte desenvolvimento industrial devido à desconcentração da Região Metropolitana de São Paulo. Barbi (2007) mostra que as atividades de abastecimento são responsáveis pela maior parcela do consumo da água captada nas bacias PCJ, representando 42\% do total de 41.331 $\mathrm{m}^{3} / \mathrm{s}$ de vazão. Já o setor industrial ocupa o segundo lugar, com $35,2 \%$, enquanto a irrigação é responsável por 22,1\% do consumo total (Irrigart, 2007; Comitês PCJ, 2009).

Além disso, a disponibilidade de água é fortemente afetada pela reversão de suas águas para abastecimento da Região Metropolitana de São Paulo. Cerca de $31 \mathrm{~m}^{3} / \mathrm{s}$ são revertidos para a RMSP (Campos, Bortolazzo e Oliveira, 2010:2). Em função dos desafios enfrentados para manter a sustentabilidade hídrica na região, já em 1998, uma iniciativa dos prefeitos de Piracicaba e Bragança Paulista propôs a articulação de alguns municípios, resultando na criação do Consórcio das Bacias dos rios Piracicaba, Capivari e Jundiaí. Três anos depois, instala-se o Comitê PCJ instituindo-se então um espaço para a participação de usuários e criação de estratégias, propiciando uma gestão participativa dos recursos hídricos da região (Goulart Junior, Cardoso Neto e Frank, 2010). 
A instauração da cobrança do uso da água foi um dos principais temas debatidos no comitê. A cobrança incide sobre o uso dos recursos hídricos, independentemente do tipo de usuário, com exceção para os pequenos e microprodutores rurais. O valor cobrado é estabelecido em função dos objetivos definidos na Política Nacional de Recursos Hídricos (PNRH), tais como: a) obter recursos financeiros para o financiamento dos programas e intervenções contemplados nos planos de recursos hídricos; b) incentivar a racionalização do uso da água; c) reconhecer a água como bem econômico dando ao usuário uma indicação de seu real valor (Ana, 2009:47).

Porém, como os interesses dos integrantes dos comitês são diversificados, a definição do valor ocorre após um exaustivo processo político de negociação. Por esse motivo, países como a França optaram por uma implementação gradativa da cobrança, sendo os preços ajustados ao longo do tempo (Porto, 2003; Comitês PCJ, 2009; Daee, 2010).

No PCJ, a instalação da cobrança foi precedida por um projeto piloto iniciado pelo Consórcio PCJ. Jacobi e Barbi (2007) mostram que a experiência pioneira da criação do consórcio, integrando representantes das empresas, governo e da sociedade civil, foi fundamental para criar uma cultura de diálogo entre os diferentes atores sociais em busca de soluções para os graves problemas de água enfrentados pela região.

Esse processo contribuiu para diversos avanços na gestão de recursos hídricos na região, incluindo a definição dos preços da cobrança para os diferentes tipos de consumo. A cobrança total é calculada por meio da soma do volume de água captada, do volume de água não devolvida e do tipo de poluente lançado nas águas (Leite e Vieira, 2010; Ramos, 2007). Além disso, em face do volume de água significativo que é transferido da região para o sistema Cantareira, estabeleceu-se um preço específico para essa atividade. O quadro 1 mostra o preço unitário da cobrança.

Quadro 1

Valores de cobrança nas bacias PCJ

\begin{tabular}{|llll|}
\hline Tipo Uso & PUB & Unidade & PUBs (R\$) \\
\hline Captação de água bruta & PUBCAP & $\mathrm{R} \$ / \mathrm{m}^{3}$ & 0,01 \\
Consumo de água bruta & PUBcons & $\mathrm{R} \$ / \mathrm{m}^{3}$ & 0,02 \\
Lançamento de carga orgânica DBO 5,20 & PUBDBO & $\mathrm{R} \$ / \mathrm{kg}$ & 0,10 \\
Transposição da bacia & PUBTRANs & $\mathrm{R} \$ / \mathrm{m}^{3}$ & 0,015 \\
\hline
\end{tabular}

Fonte: Martinez e Lahoz (2007:5).

Embora a cobrança paulista tenha sido aprovada antes da federal, ela só foi implementada um ano depois. Para Demajorovic e Caruso (2012), a cobrança paulista não figurou como prioridade nas pautas políticas dos respectivos municípios envolvidos. A tabela a seguir indica os valores totais arrecadados no PCJ no período de 2006 a 2013 a partir das diferentes modalidades de cobrança. 
Tabela 1

Valores anuais arrecadados com as cobranças PCJ em R\$

\begin{tabular}{|ccc|}
\hline Ano & Cobrança Federal & Cobrança Paulista \\
\hline 2006 & $10.016 .779,37$ & 0 \\
2007 & $13.499 .321,85$ & $8.761 .303,98$ \\
2008 & $17.038 .837,82$ & $12.595 .098,79$ \\
2009 & $16.955 .757,89$ & $15.584 .099,46$ \\
2010 & $17.556 .783,42$ & $18.338 .431,79$ \\
2011 & $16.515 .708,30$ & $16.838 .970,57$ \\
2012 & $18.116 .075,82$ & $17.677 .619,98$ \\
2013 & $17.551 .377,26$ & $16.839 .304,74$ \\
Total & $127.250 .641,73$ & $106.634 .829,31$ \\
\hline
\end{tabular}

Fonte: Elaborada pelos autores, adaptada de Ana (2014:1).

A tabela mostra que a cobrança se expande de 2006 a 2008 em função de muitos enquadramentos e cadastros novos. A partir de 2008 seu valor se estabiliza, o que explica a menor variação no período subsequente. As informações disponíveis mostram também que, passados cinco anos desde a implantação da cobrança federal e quatro da cobrança estadual, os recursos arrecadados já são revertidos para as bacias hidrográficas do PCJ, destacando-se os investimentos em afastamento e tratamento de esgoto, conforme o gráfico 1.

Gráfico 1

Aplicação de recursos das cobranças federal e paulista

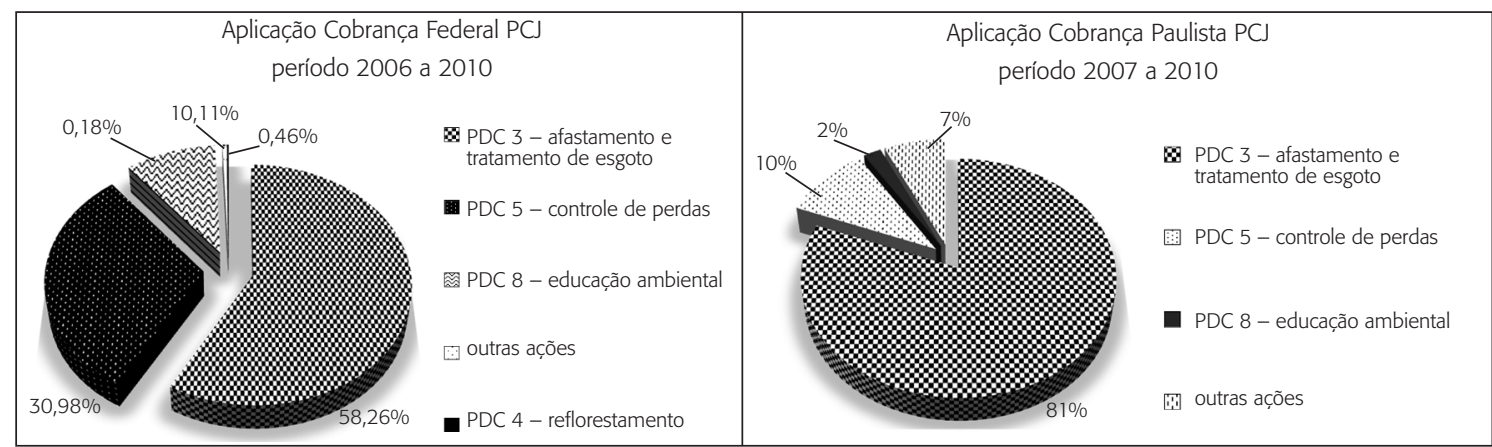

Fonte: Elaborado pelos autores, adaptado de John e Marcondes (2010:69).

Apesar da cobrança ser considerada um grande avanço no que se refere à gestão dos recursos hídricos na região, Quental, Bombo e Yansen (2010) argumentam que não gera recursos suficientes para atender às necessidades de garantia de qualidade e disponibilidade de água na bacia. A discussão sobre a insuficiência de recursos em face das demandas de dis- 
ponibilidade e qualidade da água suscita uma segunda questão que se refere à contribuição de cada grupo de usuários para a construção desse montante, como pode ser observado na tabela 2.

Tabela 2

Resumo de valores da cobrança do PCJ em rios de domínio da União, por setor, de 2006 a 2009

\begin{tabular}{|c|c|c|c|c|c|c|}
\hline \multirow{2}{*}{ Setor } & \multirow{2}{*}{$\begin{array}{l}\text { № de } \\
\text { usuários }\end{array}$} & \multicolumn{4}{|c|}{ Valores nominais $(\mathrm{R} \$)$} & \multirow{2}{*}{$\begin{array}{c}\text { Valores efetivos } \\
\text { (R\$) }\end{array}$} \\
\hline & & Captação & Consumo & DBO & Total & \\
\hline Saneamento & 25 & $2.428 .259,61$ & $1.320 .090,49$ & $1.083 .397,42$ & $4.831 .747,52$ & $4.764 .838,84$ \\
\hline Indústria & 55 & $1.589 .215,46$ & $590.004,53$ & $189.281,41$ & $2.368 .501,40$ & $2.334 .291,99$ \\
\hline $\begin{array}{l}\text { Irrigação / Criação } \\
\text { animal }\end{array}$ & 14 & $2.493,09$ & $3.757,28$ & 7,08 & $6.257,45$ & $6.293,27$ \\
\hline Transposição & 1 & $9.290 .605,01$ & 0,00 & 0,00 & $9.290 .605,01$ & $9.290 .605,01$ \\
\hline Outros & 6 & $548.871,33$ & 295,68 & $1.331,82$ & $550.498,83$ & $550.501,57$ \\
\hline Total & 101 & $14.352 .060,70$ & $1.914 .147,98$ & $1.274 .017,73$ & $17.540 .226,41$ & $16.946 .531,58$ \\
\hline
\end{tabular}

Fonte: Elaborada pelos autores, adaptada de Ana (2012:1).

O maior valor cobrado pela bacia dos rios PCJ, R\$ 9 milhões em 2009 ou 55\% valor do total arrecadado, se refere à transposição de águas para o Sistema Cantareira na região metropolitana do estado de São Paulo (RMSP). Em seguida, aparece o setor de Saneamento com $\mathrm{R} \$ 4,7$ milhões ou 27\%. A Sabesp configura-se então como o usuário que mais paga pela cobrança pelo uso da água no PCJ. No caso do setor industrial, mesmo sendo o segundo maior usuário de recursos da região, sua contribuição por meio das 55 empresas cadastradas é de R\$ 2,3 milhões ou 7,2\% dos recursos arrecadados. Além disso, um cálculo do desembolso médio do conjunto de empresas para o mesmo período resultou em $\mathrm{R} \$ 42.000,00$ ou pouco mais de R\$ 10 mil ao ano. Valores tão reduzidos evidenciam a necessidade de entender se a cobrança está efetivamente contribuindo para a racionalização dos recursos hídricos no setor industrial. Registra-se que, no caso francês, Borges (2008) afirma que o valor da cobrança aumentou progressivamente ao longo de 40 anos, representando um crescimento de cerca de 20 vezes na arrecadação. Somente no período de 1992 a 1996, o valor da cobrança foi triplicado (Glachant, 2002). Como resultado, observou-se uma diminuição de lançamentos de carga orgânica, sólidos suspensos e substâncias tóxicas. Especificamente quanto ao lançamento de cargas poluentes de origem industrial, verificou-se uma redução substancial e estável ao longo dos anos nessa atividade, desde a implantação da cobrança no início da década de 1970 (Barraqué, 1995). Importante destacar que o estudo da experiência francesa feito por Glachant (2002) mostrou que, mesmo considerando os sucessivos aumentos do valor da cobrança, ela ainda é baixa para influenciar o comportamento dos usuários, incluindo os industriais. No entanto, ela se mostrou um importante instrumento de incentivo à inovação para a redução 
do nível de poluentes lançados em corpos hídricos, sempre que precedida por uma revisão dos padrões de lançamento de efluentes e de qualidade da água.

Já no caso brasileiro, poucos são os estudos que se debruçaram especificamente sobre o impacto da cobrança para a modificação do comportamento dos usuários industriais. Estudos disponíveis mostram alguns resultados díspares e conclusões mais genéricas sobre a efetividade desse instrumento. Feres e colaboradores (2005), por exemplo, defendem que a cobrança da água implantada na bacia do Paraíba do Sul não influenciou o comportamento dos usuários industriais em termos de tratamento de efluentes. Concluem os autores que seu valor deveria ser reajustado significativamente nos anos posteriores à sua implantação para que esse objetivo fosse alcançado. Pio (2005) argumenta que a preparação dos usuários industriais para o mecanismo cobrança recaiu sobre um histórico de investimentos diversos e capacitação de representantes para a atuação nos comitês. Já Borges (2008:143), em seu estudo sobre a eficiência da cobrança pelo uso da água como instrumento de política ambiental, descreveu-a como "imprescindível" no que tange ao uso racional da água na indústria e atestou "a necessidade de estudos constantes sobre o comportamento do usuário das águas".

Para a autora, há a necessidade de um maior envolvimento da academia no debate sobre o uso dos recursos hídricos por parte dos usuários industriais, pois "a divulgação das informações relativas ao uso dos recursos hídricos possibilitaria um diagnóstico mais fiel do perfil do usuário industrial" (Borges, 2008:142). De forma a contribuir para esse debate, apresentam-se a seguir os procedimentos metodológicos que nortearam a pesquisa de campo e seus resultados.

\section{Procedimentos metodológicos}

Por se tratar de tema bastante recente no país, e pela carência de pesquisas específicas que o relacionam à cobrança e ao comportamento dos usuários industriais, optou-se por desenvolver um estudo qualitativo interpretativo. Para tanto, privilegiou-se discutir o fenômeno a partir da percepção dos múltiplos atores envolvidos com essa temática por meio da realização de um estudo de caso. Para Eisenhardt (1989), a exemplaridade do caso permite construir hipóteses sobre temas pouco pesquisados. É exatamente o caso desta pesquisa, pois são limitados os trabalhos abordando o tema do impacto da cobrança especificamente sobre o comportamento do setor industrial. Justifica-se a escolha do PCJ como objeto de estudo por ser uma referência nacional com relação ao processo de implantação da cobrança do uso da água.

A técnica de coleta de dados privilegiou a análise de documentos e a realização de entrevistas semiestruturadas. Muitos dos documentos analisados são de acesso público, outros foram fornecidos por agentes governamentais, empresas participantes e representantes de organizações não governamentais. Atas de reunião das várias câmaras técnicas e assembleias do Comitê PCJ foram analisadas, complementadas por observações in loco dessas reuniões. Entre os documentos, priorizaram-se os que foram produzidos pelo comitê de bacia do PCJ e da ANA que detalham os processos de implantação da cobrança na região escolhida para o estudo. 
Já a entrevista semiestruturada foi escolhida por se adaptar melhor aos objetivos deste trabalho. A seleção dos entrevistados se deu a partir da identificação de um grupo de atoreschave que atuassem no comitê do PCJ e que representassem os múltiplos interesses presentes no comitê. Além disso, a técnica snow-ball ou bola de neve agregou nomes ao método de amostragem não probabilístico escolhido (Godoi e Mattos, 2010). Foram realizadas 20 entrevistas, sendo oito com entidades governamentais (G1 a G8), oito gestores industriais (I1 a I8), dois representantes de entidades empresariais (EE1 a EE2), uma ONG de trabalhos de reflorestamento na margens dos rios da bacia (O1) e uma de instituição universitária (U1). O critério de "saturação teórica" ou "redundância" definido por Glaser e Strauss (1967) mostrou que a amostra escolhida foi suficiente para uma discussão abrangente e aprofundada da temática escolhida.

Dezoito entrevistas presenciais e duas via comunicador instantâneo (Skype) foram realizadas e transcritas. Nas demais, quando a gravação não foi permitida, as anotações do pesquisador representaram a base para análise de dados. As entrevistas atingiram a média de 50 minutos, sendo realizadas no segundo semestre de 2011 e primeiro de 2012. As transcrições foram enviadas para os entrevistados para validação, sendo autorizado o uso das informações pelo conjunto de respondentes. Do total dos entrevistados, quatro representantes industriais solicitaram que os nomes das empresas não fossem divulgados, optando-se por não identificar nenhuma das fontes de informações.

As entrevistas foram transcritas para sua posterior análise, sendo a técnica escolhida para essa fase a de análise de conteúdo. Seguindo a recomendação de Bardin (1994), categorias e subcategorias foram criadas para facilitar o processo de análise a partir da revisão da literatura e do processo de análise das entrevistas.

Quadro 2

\section{Relação de categorias e subcategorias}

\begin{tabular}{|c|c|}
\hline Categorias & Subcategorias \\
\hline $\begin{array}{l}\text { Importância da cobrança como instrumento na gestão. } \\
\text { (Guimaraes et al., 1995; Seroa da Mota, 2006; Varela, 2008; } \\
\text { Brasileiro et al., 2010) }\end{array}$ & Qualidade de água e conscientização ambiental \\
\hline $\begin{array}{l}\text { Processo de instalação da cobrança nas bacias do PCJ (Porto, } \\
\text { 2003; Pio, 2005; Daee, 2010; Comitês PCJ, 2009) }\end{array}$ & $\begin{array}{l}\text { Instituição do Comitê PCJ e da Agência de Águas; } \\
\text { embates e conflitos; preparação dos usuários industriais; } \\
\text { cálculo do preço }\end{array}$ \\
\hline $\begin{array}{l}\text { Indução à mudança (Barraqué, 1995; Feres et al., 2005; Borges, } \\
\text { 2008; Varela, 2008) }\end{array}$ & $\begin{array}{l}\text { Efetividade; relação com outros instrumentos de gestão; } \\
\text { valores; qualidade da água }\end{array}$ \\
\hline $\begin{array}{l}\text { Relações participativas (Martinez e Lahoz, 2007; Igam, 2006; } \\
\text { Goulart Junior, Cardoso Neto e Frank, 2010), }\end{array}$ & $\begin{array}{l}\text { Estrutura do Comitê PCJ; perfil profissional de seus } \\
\text { membros; conflitos e interação; definição de projetos }\end{array}$ \\
\hline $\begin{array}{l}\text { Aplicação da cobrança (Quental, Bombo e Yansen, 2010; John e } \\
\text { Marcondes, 2010) }\end{array}$ & $\begin{array}{l}\text { Prioridades de destinação; resultados da aplicação; } \\
\text { futuro da aplicação dos recursos }\end{array}$ \\
\hline $\begin{array}{l}\text { Transposição das águas Sistema Cantareira (Campos, Bortolazzo e } \\
\text { Oliveira 2010) }\end{array}$ & $\begin{array}{l}\text { O futuro da cobrança no PCJ; outorga do Sistema } \\
\text { Cantareira }\end{array}$ \\
\hline
\end{tabular}

Fonte. Elaborado pelos autores. 
Após esta etapa, foram selecionados fragmentos de textos que, após serem codificados, transcritos e tabulados, são apresentados a seguir com seus comentários e análises reflexivas. Destaca-se ainda que os fragmentos apresentados incluem apenas conteúdos de transcrições, sendo as anotações das entrevistas usadas na complementação do texto corrido nas partes de resultados e discussão.

\section{Resultados da pesquisa de campo}

A primeira pergunta nas entrevistas avaliou a percepção dos entrevistados a respeito da cobrança pelo uso da água como instrumento de gestão. A totalidade dos atores é favorável ao instrumento, e pelo menos metade deles classificam-no como essencial. A importância inclui a identificação dos usuários e sua responsabilização da gestão, bem como o empoderamento do Comitê que passa a ter voz ativa na gestão dos recursos hídricos na localidade. A cobrança representa também um importante passo na evolução do controle ambiental e da qualidade das águas das bacias do PCJ, complementando a aplicação de outras ferramentas ambientais já utilizadas na região.

Eu avalio a cobrança como importante, uma vez que responsabiliza os envolvidos na gestão do recurso hídrico com os resultados da gestão na própria bacia onde estão inseridos. (EE2)

A cobrança é um mecanismo econômico de gestão e tem uma importância. Os instrumentos econômicos têm uma importância muito grande na evolução do controle ambiental. (U1)

Outro elemento importante é o reconhecimento dos limites da abordagem exclusiva de comando e controle, sendo na visão dos entrevistados essencial complementar com outros instrumentos como os de mercado. Além disso, os próprios representantes empresariais reconhecem que a chegada da cobrança como um importante instrumento de conscientização na medida em que princípios como o de poluidor e, principalmente, o de usuário pagador, caracterizado pelo pagamento pelo acesso a esse recurso natural, fossem mais bem compreendidos pelos atores da bacia:

Quando a gente inicia o controle ambiental, o instrumento de comando e controle precisa entrar primeiro porque ele precisa ser um instrumento de disciplinamento. Mas no momento em que você reconhece que a eficiência dele tem um teto, você precisa começar a entrar com mecanismos de incentivo para aumentar a adesão, para aumentar a aderência às metas que você quer obter no sistema. (G6)

A água tem valor econômico, com a Lei 9433/97, e agora, com a cobrança, as empresas finalmente entendem isto. Cobra-se pela captação, pela poluição, pelo lançamento de efluentes. Não é mais só pelo uso. (I3) 
Com relação ao processo de implantação da cobrança, os entrevistados acreditam que hoje a experiência do PCJ serve de modelo para o país. Ressaltam uma especificidade dessa experiência que foi a participação prévia de parcela dos membros do comitê em conselhos multistakeholders, como o caso do Consórcio PCJ, e beneficiou muito o processo de instalação da cobrança na região.

Ele tem uma organização mais importante do que os demais comitês, não resta dúvida. O problema é praticamente histórico, da Bacia. O processo de organização do PCJ vem desde a década de 1980. Antes mesmo da existência do comitê PCJ, essa organização na Bacia já existia, em função da disponibilidade hídrica, dos problemas de poluição que já existiam. O Consórcio era tão experiente nos problemas, que virou Comitê. (G4)

No consórcio intermunicipal esses atores precisam pagar para ser sócios. E esse consórcio tem uma atuação muito forte, tanto política como tecnicamente aqui na região. As coisas ficaram muito facilitadas para o comitê aqui, justamente porque existia esse consórcio. Isso é inegável. Nas outras regiões que você não tem isso, as coisas ficam mais difíceis. Então, o comitê falou: "Consórcio, você topa fazer esse papel para a gente?" (I3)

Apesar do papel importante desempenhado pelo consórcio para facilitar o processo de implantação da cobrança no PCJ, a análise das informações levantadas mostra também embates e conflitos importantes que emergiram nesse processo, como a ameaça de evasão de alguns usuários industriais da região. De acordo com o relato de alguns entrevistados, conflitos ocorreram entre os órgãos governamentais e os usuários industriais quando das primeiras reações à cobrança, sem nem mesmo entender na íntegra do que tratava o instrumento.

Para nós era só mais uma taxa. Só mais um custo. Estávamos no escuro e não podíamos prever os custos reais da cobrança. Não tínhamos ideia da representatividade disso no nosso negócio. (I8)

Muito difícil. Os primeiros comentários que ocorreram quando a gente foi discutir a cobrança lá. Os industriais falando que iam ser obrigados a sair da Bacia. (G2)

Para reduzir os conflitos, optou-se por manter valores baixos, a fim de garantir a adesão. O maior objetivo era introduzir a cobrança federal, estabelecer os procedimentos relacionados e alinhá-la de forma a representar um instrumento organizado, claro, aceito e consolidado entre os usuários industriais.

A resistência? Geral. Todo mundo que lidava com avaliação econômica, científica dizia: "Ah, mas qual vai ser o impacto? Que esses valores provavelmente sejam pequenos". Eu falei: "Realmente”. E nós dizíamos, aqui na região: "A cobrança não vai ser implantada em cima daquilo que nós queremos. Ela vai ser implantada em cima daquilo que nós podemos". (G6) 
Outro tipo de embate evidenciado na instalação da cobrança foi a aplicação dos recursos da arrecadação nos primeiros anos. Ainda que os planos de bacia assegurem que investimentos para a melhoria da qualidade da água sejam realizados na bacia, os interesses conflitantes entre os membros emergem no momento de definição de prioridades.

Com relação à principal pergunta desta pesquisa, é interessante destacar que, embora a literatura apresentada defenda que instrumentos econômicos possam ser eficientes como indutores da mudança de comportamento dos usuários industriais, praticamente a totalidade dos atores entrevistados não reconhece isso como um resultado efetivo da cobrança no PCJ. A principal razão estaria no baixo valor que incide efetivamente sobre os custos da empresa com a adoção da cobrança. Assim, o menor impacto é justamente no setor industrial, pois os valores estabelecidos foram facilmente assimilados pelas empresas. A razão disso está no fato de a posição empresarial nos debates no comitê ressaltar sempre o medo do impacto dos custos financeiros das empresas:

Como os valores são baixos, eles podem ser facilmente assimilados pelo setor industrial. O setor industrial é o setor que tem o menor impacto da cobrança entre todos os setores. (G1)

A eficácia do instrumento está muito voltada ao preço cobrado. Se o preço cobrado é baixo, ele não promove o incentivo que eu quero que ele promova. Se o preço cobrado é baixo, o industrial vai fazer a conta, dizendo o seguinte: "Vale a pena eu implantar um sistema de reúso de água para diminuir a minha conta do pagamento ou não?". Se o preço é baixo, ele fala: “Não, não vale a pena. Vale a pena eu pagar e não implantar nenhum sistema de reúso". E isso eu acho que é uma coisa que está acontecendo no Brasil, de uma maneira geral. Os preços praticados são muito baixos. (U1)

Para nós era só mais uma taxa. Só mais um custo. Estávamos no escuro e não podíamos prever os custos reais da cobrança. Não tínhamos ideia da representatividade disso no nosso negócio. (I7)

A cobrança estimula isso, um refletir no uso da água. Apesar do valor não ser um impacto tão significativo. Muitas vezes não é nem repassado para o usuário. (EE1)

Nesse contexto, a revisão do preço da cobrança é considerada essencial para que possa efetivamente induzir a mudança de comportamento dos usuários industriais. Para alguns entrevistados, a inadimplência do sistema em 0,5\% é um forte indicador do baixo impacto da cobrança nos custos dos usuários. Importante ressaltar que, conforme dados fornecidos pelo Comitê PCJ e apontados pelos stakeholders, a definição do preço público unitário (PPU) da cobrança foi definida pelos próprios usuários, desconsiderando qualquer tipo de estudo econômico ou processo de formação de preço na elaboração dos valores finais e culminando em um valor irrisório para muitos deles.

Passados seis anos da cobrança, o que a gente está percebendo é que, de uma forma geral, não houve redução muito significativa nos usos, tanto em termos de melhoria da eficiência, como em termos de redução das cargas lançadas, de forma geral. (G2) 
Por exemplo, o PCJ se orgulha muito que tem uma adimplência de, sei lá, 95\%. Eu acho muito estranho ter uma adimplência de $95 \%$. Tem alguma coisa errada nesse processo. Não vamos, aqui, tirar o mérito do PCJ. O PCJ é uma bacia em que os usuários são muito cientes da questão ambiental. Mas essa adimplência de $95 \%$ não é porque os usuários são bonzinhos, todo mundo quer pagar e todo mundo quer ajudar. É porque o preço é baixo. (U1)

Revisar os preços, segundo alguns atores, requer uma série de estudos e negociações, pois é possível que se aplique um preço tão alto que resulte em uma situação negativa, como a evasão de empresas da região. Apesar do entendimento da maior parte dos entrevistados sobre a necessidade de revisão dos preços, persiste no setor empresarial uma resistência à elevação dos valores. Nesse aspecto, a revisão retoma os conflitos do início da cobrança separando o setor industrial dos demais. Além disso, o argumento dos empresários hoje é embasado no fato de o saneamento ser hoje considerado o maior desafio da bacia, assim como o fato de parcela de recursos não reverterem para projetos do setor empresarial, representando a possibilidade do retorno financeiro direta ou indiretamente para a indústria.

Segundo o que tenho acompanhado nesse trabalho com o pessoal da Agência e do Comitê e outras unidades, o que eu tenho visto é que a indústria sempre paga a conta. E já foi colocado isso algumas vezes, como o próprio trabalho que a Agência e o Comitê fizeram, 92\% da carga orgânica da indústria já é abatida. E a pergunta que fica, e que a gente não vê uma solução, nem a médio e nem a longo prazo, nem a perder de vista, é quando o Estado vai fazer o seu papel? (E8)

Se a indústria pode ajudar com dinheiro em tratamento de esgoto da região, porque na hora do empresário investir em equipamentos e ajustes do seu negócio, ele não poderia usar o dinheiro da cobrança? Faz todo o sentido ter uma via de duas mãos nesse processo. (EE2)

Ainda que a maior parte dos entrevistados concorde com o desafio do saneamento, argumentam que a cobrança precisa gerar recursos adicionais para a expansão dessa atividade, tornando a elevação dos preços essencial para atingir os objetivos do uso do instrumento. Isso não impede que, com a evolução dos debates, abram-se novas possibilidades de que as próprias indústrias sejam também beneficiadas com uso de parcela dos recursos arrecadados, para investimentos em melhorias de seus processos como ampliação de Estações de Tratamento de Efluentes.

O grande problema de poluição de Piracicaba é o esgoto. As cidades vão crescendo, as cidades vão se expandindo, a população vai crescendo. Se você não tem um investimento forte em coleta e tratamento de esgoto, piora mesmo a poluição. (U1)

Na verdade, hoje, no Fehidro, na cobrança paulista, a indústria pode ser beneficiada, pode captar dinheiro da cobrança paulista para aplicar em ações de tratamento de esgoto e outras previstas no plano, dentro da empresa. No Fehidro já existe, é um recurso que a indústria pode pegar como financiamento com retorno e ela paga juros, a TJLP mais $2 \%$. (G5) 
Apesar dos desafios enfrentados pela cobrança pelo uso da água desde sua criação, a percepção unânime dos atores aponta que, mesmo não sendo efetiva, a cobrança contribuiu e continua contribuindo muito para a questão da qualidade da água, pois a recuperação dos mananciais representa um benefício coletivo.

Eu encaro como positivo, até porque a gente ouve relato do nosso pessoal sobre as atividades, que a qualidade do rio vem melhorando, algumas espécies de peixes já conseguem ser vistas no rio, que não se via há muito tempo. Isso mostra o resultado desse trabalho. A qualidade da água melhorando, ela impacta diretamente no nosso processo. (I5)

Além disso, mesmo não sendo reconhecida como efetivo indutor da mudança do comportamento industrial, as entrevistas revelaram que a instalação da cobrança acabou favorecendo uma revisão efetiva das outorgas para os usuários industriais do PCJ. A cobrança fez com que o usuário identificasse realmente quanto recurso necessitava e, em muitos casos, isto resultou em uma redução do direito de uso da água. Tal fato permitiu que os órgãos públicos obtivessem dados mais apurados sobre o consumo na bacia, já que em muitos casos a outorga evidencia-se como muito maior do que a necessidade do usuário.

Com o início da cobrança houve um movimento dos usuários no sentido de revisar suas outorgas, diminuindo as vazões, para ajustar a vazão autorizada, outorgada, àquilo que ele realmente estava usando. E por que isso é importante? Porque nós trabalhamos aqui na ANA e nos órgãos gestores estaduais, sempre considerando as vazões outorgadas. (G2)

O impacto foi no planejamento, na outorga. Não adianta pedir mais outorgas que não vai ter mais disponibilidade de água, principalmente para o setor privado. (I8)

A outorga e os planos de bacias aprovados pelos Comitês PCJ emergem nas entrevistas como mais importantes do que a própria cobrança, reforçando o argumento da complementaridade dos instrumentos de gestão de recursos hídricos aplicados na região.

Acompanhamos através de reuniões junto ao comitê o gerenciamento dos recursos aplicados e entendemos que os mesmos estão sendo aplicados de forma necessária e racional, porém entendemos que, devido às necessidades de recuperação e manutenção, somente a cobrança não é suficiente para realizar as ações necessárias. Outros instrumentos devem ser utilizados. (I4)

Em meio a esse debate, a maior e mais importante outorga da região das Bacias PCJ, a do Sistema Cantareira na RMSP, emergiu como um ponto crucial para os stakeholders durante as entrevistas. No entanto, a renovação que deveria ter acontecido em 2014, devido à severidade da crise hídrica vívida no estado de São Paulo, não foi renovada. Independente desse fato, as falas aqui apresentadas já indicavam os complexos desafios para o PCJ e a cidade de São Paulo, mesmo antes da prolongada estiagem de 2014. 
Outras formas estão sendo pensadas para compensar onde não estaríamos mais com essa atribuição de fazer essa reserva para o Sistema Cantareira. Isso já foi discutido também e apresentado por pessoas que estão no PCJ e discutem bastante sobre essa questão. Vai ter que se buscar outras formas para abastecer a Grande São Paulo, porque o interior é o grande polo de desenvolvimento e essa demanda não vai ser possível para os próximos anos. (I2)

A situação dos recursos hídricos nas bacias hidrográficas dos rios Piracicaba, Capivari e Jundiaí nos próximos 15 anos, é que a BH-PCJ será uma bacia hidrográfica fechada; para 2030, a situação na bacia será extremamente complicada tal como indicam os coeficientes calculados; para 2050, a situação será muito próxima de não ser sustentável. (G4)

Nesse cenário, onde o agravamento dos recursos hídricos é compartilhado pela totalidade dos entrevistados nesta pesquisa, aprimorar o funcionamento integrado dos instrumentos de gestão de recursos hídricos apresentados torna-se fundamental para garantir que a água nas próximas décadas não se constitua em um fator limitante para o desenvolvimento da bacia.

\section{Conclusão}

A principal finalidade deste trabalho foi verificar como a cobrança do uso da água está contribuindo para modificar o comportamento dos usuários industriais na região das bacias hidrográficas do PCJ.

Isto decorre da constatação de diversos atores de que, ao se atribuir valor econômico à água, esse mecanismo de mercado se torna um forte indutor da mudança de comportamento dos usuários de recursos hídricos. Trabalhos de Borges (2008) e Barraqué (1995) reforçam essa tese ao defenderem que os instrumentos econômicos têm se mostrado eficientes não só quanto à mudança de comportamento, mas também quanto ao uso racional dos recursos hídricos pelos vários tipos de usuários, inclusive industriais. No entanto, a pesquisa de Glachant (2002), embora reconheça a importância da cobrança para estimular melhorias em processos preventivos, considera que sua eficácia depende da elevação de preço e da atualização dos padrões de qualidade de efluentes.

Já no caso do PCJ, o relato dos atores entrevistados demonstrou que a cobrança pelo uso da água não modifica o comportamento dos usuários de forma direta, embora o instrumento seja também reconhecido por todos como essencial para a gestão de recursos hídricos na região. Em meio a esses aspectos, a principal questão aponta para o preço da cobrança pelo uso da água, considerado irrisório por muitos usuários, independentemente do âmbito federal ou estadual. Valores que não ultrapassam mil reais mensais para empresas de médio e grande porte apresentam-se como extremamente tímidos em face da importância do setor industrial no uso dos recursos hídricos na região. Como exemplo, uma empresa da amostra que obteve um faturamento anual superior a R\$ 60 milhões em 2010 pagou cerca de 0,04\% 
desse total pela cobrança do uso da água nesse mesmo ano. Destaca-se a convergência dos resultados desta pesquisa com a de Feres e colaboradores (2005), em seu estudo do impacto da cobrança nos usuários industriais na bacia do Paraíba do Sul. Além disso, o baixo valor da cobrança resulta em volumes de arrecadação ainda pequenos diante das demandas da região.

Cabe destacar que, nos países europeus, como no exemplo francês citado, taxas pequenas iniciais também foram utilizadas. Ao longo do tempo, porém, como mostraram os estudos de Barraqué (1995) e Glachant (2002), o reajuste do valor da cobrança foi fundamental para que o instrumento cumprisse seus objetivos na França. No caso do PCJ, apesar de os valores serem muitos baixos, a resistência do setor empresarial tem logrado evitar qualquer modificação nos preços atuais. Não se trata de um questionamento da metodologia empregada na cobrança, mas sim exclusivamente do preço final efetivo a ser pago, opondo a posição do setor empresarial à dos demais setores representados nas entrevistas. O trabalho revela também uma visão enviesada da cobrança quando alguns dos entrevistados defendem que é preciso mostrar que a cobrança não gera impacto nas empresas. No entanto, conforme Seroa da Motta (2000), o que se espera é justamente que a cobrança gere impactos e mobilize os usuários a modificar seu comportamento. Ainda assim, ela não pode ser vista como apenas mais uma taxa ou imposto, com interesse puramente arrecadatório, como mostrou a percepção dos usuários industriais. Como afirmam Canepa e colaboradores (1999), Silveira e Goldenfrum (2009) e John e Marcondes (2010), trata-se de um pagamento pela utilização de um bem público. Importante lembrar que o modelo da cobrança possibilita diminuir o montante a ser pago, sempre que o investimento na racionalização dos recursos hídricos seja feito. O reúso da água, por exemplo, contribui tanto para a redução de captação de água como de lançamento de efluentes.

Nesse contexto, apesar da participação ativa dos múltiplos stakeholders nos debates conduzidos pelo Comitê PCJ, a revisão do preço da cobrança pelo uso da água surge como um fator de tensão entre usuários, poder público e organizações não governamentais, no qual as disputas políticas internas nos comitês repercutem negativamente e devem ser neutralizadas pelo Comitê de Bacia sempre que possível, garantindo a eficácia dos trabalhos.

Ainda assim, tão importante quanto a indução da mudança comportamental, a pesquisa mostra que é preciso ampliar os recursos disponíveis para investimentos na bacia, corroborando Quental, Bombo e Yansen (2010). Melhorar a condução dos projetos surge também como um elemento importante para o aprimoramento do uso do instrumento, como apontaram vários entrevistados.

É interessante então perguntar: qual seria a validade da cobrança? Na bacia estudada, a implantação da cobrança deu continuidade a um processo participativo iniciado no trabalho do consórcio, conforme indicado e ressaltado no trabalho de Martinez e Lahoz (2007) e reafirmado pelos entrevistados. Com o advento da cobrança e a perspectiva de gerar recursos para serem investidos na própria bacia, ampliou-se ainda mais o interesse dos múltiplos stakeholders em participarem ativamente das discussões dentro do Comitê, corroborando os argumentos de Martinez e Lahoz (2007). Também este estudo corrobora a argumentação de Pio (2005) de que a preparação dos usuários industriais para a cobrança resultou em ações 
efetivas para melhorias das práticas de gestão da água nas empresas. É possível inferir que a cobrança potencializou o debate e as ações na gestão de recursos hídricos na bacia, beneficiadas por características específicas dessa região no que se refere à experiência em processos participativos. Como resultado, foi possível avançar na questão da implantação da cobrança e diminuir a resistência inicial do setor empresarial contrário à adoção do instrumento. Destaca-se também o papel da cobrança em contribuir para a melhoria da efetividade de outros instrumentos complementares, tais como a outorga e os planos de bacia, reforçando os argumentos de Bafoni e Telles (2010) e Veettil e colaboradores (2011) sobre os benefícios para a gestão de recursos hídricos quando os diversos instrumentos atuam de forma sincronizada.

O debate e implantação da cobrança, por exemplo, reforçaram a efetividade da outorga, na medida em que geraram a revisão do direito do uso do recurso hídrico disponível versus o volume de água necessário a cada usuário industrial. Gestores públicos e privados se beneficiaram de dados atualizados sobre os volumes e tipos de uso efetivo da água no PCJ.

Diante de tal cenário, há a necessidade de avançar os estudos que relacionem a cobrança e o comportamento do setor industrial, em face de sua importância como usuário de recurso hídrico na região. Entre os trabalhos futuros destaca-se a revisão dos preços hoje aplicados ao setor industrial, de forma a identificar um valor para o consumo de recursos hídricos que possa contribuir para reduções mais significativas no uso da água nas empresas e para a geração de mais recursos para programas de qualidade ambiental. Além disso, sugerem-se também estudos que foquem a implantação de mecanismos que possam reverter parcela dos recursos arrecadados para as empresas de forma a incentivar a melhoria contínua de seu desempenho ambiental na gestão hídrica. Por fim, um elemento também a se considerar na realidade brasileira é a relação entre elevação de padrões de qualidade de efluentes e da água e a efetividade da cobrança, conforme defendido por Glachant (2002) no caso francês.

Conclui-se que, apesar dos avanços observados na região advindos do processo de implantação da cobrança, a revisão do preço é uma variável fundamental para tirar os usuários industriais da situação de conforto atual. Se, para a viabilização da cobrança, os preços baixos estabelecidos foram essenciais para garantir a adesão do setor empresarial, viabilizando sua implantação e também estimulando melhorias da gestão de recursos hídricos nas empresas, permanecem desafios que indicam a necessidade de aprimorar o instrumento. A continuidade do desenvolvimento urbano-industrial da região, a relação com a RMSP e a necessidade de gerar mais recursos para garantir a sustentabilidade hídrica da região demandam um olhar mais amplo e sistêmico da problemática da água na região. Melhorar o instrumento da cobrança e integrá-lo com outros instrumentos disponíveis torna-se essencial para lidar com os desafios hídricos da região. 


\section{Referências}

ANA. Agência Nacional de Águas. A implementação da cobrança pelo uso de recursos hídricos e agência de água das bacias dos rios Piracicaba, Capivari e Jundiaí. Brasília: ANA; SDAG, 2009.

ANA. Agência Nacional de Águas. Balanço de arrecadação efetiva: por setor, atualizado em 10/01/2012. Brasília: ANA, 2014.

ANA. Agência Nacional de Águas. Conjuntura dos recursos hídricos no Brasil — informe 2012. Brasília: ANA, 2012. Disponível em: <http://arquivos.ana.gov.br/imprensa/arquivos/Conjuntura2012. pdf>. Acesso em: 25 fev. 2015.

ANA. Agência Nacional de Águas. Gestão de bacias: instrumento de gestão. Brasília: Ministério do Meio Ambiente, 2010. Disponível em: <www.agenciadeaguapcj.org.br/\#> Acesso em: 11 jul. 2010. ANA. Agência Nacional de Águas. Relatório de atividades 2009. Brasília: ANA, 2010a.

BAFONI, Pamela; TELLES, Daniela. A cobrança pelo uso da água na bacia hidrográfica dos rios Piracicaba, Capivara e Jundiaí. In: SIMPÓSIO EXPERIÊNCIAS EM GESTÃO DOS RECURSOS HÍDRICOS POR BACIA HIDROGRÁFICA, 2., 2010, Atibaia. Anais... Brasília: ANA, 2010.

BARBI, Fabiana. Capital social e ação coletiva na gestão das bacias dos rios Piracicaba, Capivari e Jundiaí: os desafios da gestão compartilhada do Sistema Cantareira — SP. Dissertação (mestrado em ciência ambiental) — Universidade de São Paulo, São Paulo, 2007.

BARDIN, Laurence. Análise de conteúdo. Lisboa: Edições 70, 1994.

BARRAQUÉ, Bernard (Org.). Les politiques de l'eau en Europe. Paris: Éditions La Découverte, 1995.

BARRAQUÉ, Bernard; BERLAND, Jean-Marc; FLORET-MIGUET, Edith. Select emerging issues in water quality control policies. In: CORREA, Fernanda N. (Ed.). Selected issues in water resources management in Europe. Rotterdam: A. A. Balkema, 1998.

BORGES, Camila B. N. A eficiência da cobrança pelo uso da água como instrumento de gestão de recursos hídricos para as indústrias das bacias dos rios Piracicaba, Capivari e Jundiaí. Dissertação (mestrado em saúde pública) — Universidade de São Paulo, São Paulo, 2008.

BRAGA, Benedito P. F. et al. Pacto federativo e gestão das águas. Estudos Avançados: Dossiê Água, São Paulo, v. 22, n. 63, p. 17-42, maio/ago. 2008.

BRASILEIRO, Andrea C. B.; SINISGALLI, Paulo A. de A.; CICHOSKI, Caroline. Instrumentos econômicos para elaboração de políticas públicas de gestão de recursos hídricos: o caso brasileiro. In: ENCONTRO NACIONAL DA ASSOCIAÇÃO NACIONAL DE PÓS-GRADUAÇÃO E PESQUISA EM AMBIENTE E SOCIEDADE, 5, 2010, Florianópolis. Anais... São Paulo: Annpas, 2010.

CAMPOS, Elaine F.; BORTOLAZZO, Vanessa C.; OLIVEIRA, Ives. Pacto internacional das águas — estudo de águas da bacia PCJ. In: SIMPÓSIO EXPERIÊNCIAS EM GESTÃO DOS RECURSOS HÍDRICOS POR BACIA HIDROGRÁFICA, 2, 2010, Atibaia. Anais... Americana: Consórcio PCJ, 2010. 
CANEPA, Eugenio M.; PEREIRA, Jaildo S.; LANNA, Antonio E. L. A política de recursos hídricos e o princípio usuário-pagador (pup). Revista Brasileira de Recursos Hídricos da Associação Brasileira de Recursos Hídricos, São Paulo, v. 4, n. 1, p. 103-117, jan./mar. 1999.

COMITÊS PCJ. A cobrança pelo uso da água na bacia PCJ: cartilha água. 2009. Disponível em: <www.comitepcj.sp.gov.br/comitespcj.htm>. Acesso em: 7 jul. 2010.

COMITÊS PCJ. Planos de bacias 2011. São Paulo: Comitê PCJ, 2011.

DAEE. Departamento de Águas e Energia Elétrica. Cobrança pelo uso dos recursos hídricos. Piracicaba: Secretaria de Estado de Energia, Recursos Hídricos e Saneamento, 2010.

DEMAJOROVIC, Jacques; CARUSO, Carla. Uso da água na gestão de recursos hídricos das bacias hidrográficas. In: ENCONTRO INTERNACIONAL DE GESTÃO EMPRESARIAL E MEIO AMBIENTE, 16., 2012, São Paulo. Anais... São Paulo: Engema, 2012.

EISENHARDT, Kathleen M. Building theories from case studies. The Academy Management Review, v. 14, n. 4, p. 532-550, out. 1989.

FERES, José et al. Demanda por água e custo de poluição hídrica nas indústrias do Paraíba do Sul. Rio de Janeiro: Ipea, 2005.

GLACHANT, Matthieu. The political economy of water effluent charges in France: why are rates kept low? European Journal of Law and Economics, v. 14, n. 1, p. 27-43, 2002.

GLASER, Barney G.; STRAUSS, Anselm L. The discovery of grounded theory: strategies for qualitative research. Chicago: Aldine Publishing Company, 1967.

GODOI, Christiane K.; MATTOS, Pedro L. C. L. Entrevista qualitativa: instrumento de pesquisa e evento dialógico. In: GODOI, Christiane K.; BANDEIRA-DE-MELLO, Rodrigo; SILVA, Anielson B. da (Org.). Pesquisa, estratégia e métodos. 2. ed. São Paulo: Saraiva, 2010. p. 301-323.

GODOY, Mario et al. Avaliação da qualidade das águas dos principais rios formadores da bacia hidrográfica dos rios Piracicaba, Capivari e Jundiaí. In: SIMPÓSIO EXPERIÊNCIAS EM GESTÃO DOS RECURSOS HÍDRICOS DA BACIA HIDROGRÁFICA, 2, 2010, Atibaia. Anais... Americana: Consórcio PCJ, 2010.

GOULART JUNIOR, Rogério; CARDOSO NETO, Nicolau; FRANK, Beate. O mecanismo econômico para gestão de recursos hídricos - cobrança. In: ENCONTRO DE ECONOMIA CATARINENSE, 4, 2010, Santa Catarina. Anais... Santa Catarina: Apec, 2010.

GUIMARÃES, Paulo V.; DEMAJOROVIC, Jacques; OLIVEIRA, Roberto G. Estratégias empresariais e instrumentos econômicos de gestão ambiental. Revista de Administração de Empresas, São Paulo, v. 35, n. 5, p. 72-82, 1995.

IGAM. Instituto Mineiro de Gestão de Águas. Primeira etapa do Plano Estadual de Recursos Hídricos de Minas Gerais. Análise de Cenários Existentes, Relatório Técnico, Belo Horizonte, n. 3, p. 1-111, nov. 2006.

IRRIGART ENGENHARIA EM RECURSOS HÍDRICOS E MEIO AMBIENTE. Relatório final da situação dos recursos hídricos das bacias hidrográficas dos rios Piracicaba, Capivari e Jundiaí — 
2004/2006. Comitê das Bacias Hidrográficas dos Rios Piracicaba, Capivari e Jundiaí, São Paulo, v. 2, p. 126-334, 2007.

JACOBI, Pedro R.; BARBI, Fabiana. Governança de recursos hídricos e a participação da sociedade civil. In: SEMINÁRIO NACIONAL MOVIMENTOS SOCIAIS, PARTICIPAÇÃO E DEMOCRACIA, 2, 2007, Florianópolis. Anais... Florianópolis, UFSC, 2007.

JOHN, Liana; MARCONDES, Pyr. O valor da água — primeiros resultados da cobrança das bacias PCJ. São Paulo: Camirim Editorial, 2010.

LEITE, Gil B.; VIEIRA, Wislon C. Proposta metodológica de cobrança pelo uso dos recursos hídricos usando o valor de Shapley: uma aplicação à bacia do rio Paraíba do Sul. Estud. Econ. [online], v. 40, n. 3, p. 651-677, 2010.

MARTINEZ, Francisco; LAHOZ, Francisco. A cobrança pelo uso da água nas bacias hidrográficas do rio Piracicaba, Capivari e Jundiaí - aplicação e perspectivas. In: SIMPÓSIO BRASILEIRO DE RECURSOS HÍDRICOS, 17, 2007, Atibaia. Anais... Porto Alegre: ABRH, 2007.

MARTINS, Danielle P. A percepção como método para trabalhos em educação ambiental: o caso de uma comunidade de Porto Alegre — RS. In: CONGRESSO BRASILEIRO DE GESTÃO AMBIENTAL, 2, 2011. Londrina. Anais... Bauru: Ibeas, 2011.

MEJIÁS, Concepción R.; LENIHAN, Helena; O’REAGAN, Bernadette. Charges in the industrial water sector: comparison between Ireland and Spain. Environmental Resources Economics, v. 45, n. 1, p. 113-132, 2009.

OLIVEIRA, José A. P. de. Instrumentos econômicos para gestão ambiental: lições das experiências nacional e internacional. Salvador: Centro de Recursos Ambientais; Neama, 2003. (Série Construindo os Recursos do Amanhã, v. 3).

OMURA, Patrícia; MAZOCHI, Maria. A cobrança pelo uso da água na bacia Piracicaba-Jaguari (PJ): Instrumentos de gestão e metodologia de cobrança. In: SIMPÓSIO EXPERIÊNCIAS EM GESTÃO DOS RECURSOS HÍDRICOS POR BACIA HIDROGRÁFICA, 2, 2010, Atibaia. Anais... Americana: Consórcio PCJ, 2010.

PIO, Anícia A. B. Reflexos da gestão de recursos hídricos para o setor industrial paulista. Tese (mestrado em engenharia ambiental) — Universidade de São Paulo, São Paulo, 2005.

PIZAIA, Márcia G.; MACHADO, Bernardo P.; JUNGLES, Antonio E. A cobrança do uso da água e estimação da função demanda residencial de água. Rev. Adm. Pública, v. 36, n. 6, p. 847-77, 2002.

PORTO, Monica F. A. Gestão urbana e gestão das águas: caminhos da Integração. Estudos Avançados, São Paulo, v. 17, n. 47, p. 129-145, maio/ago. 2003.

QUENTAL, Sarah; BOMBO, Ivanilde; YANSEN, Karla. Aplicação dos recursos arrecadados pelas cobranças PCJ em PDCs e investimentos. In: SIMPÓSIO EXPERIÊNCIAS EM GESTÃO DOS RECURSOS HÍDRICOS POR BACIA HIDROGRÁFICA, 2, 2010, Atibaia. Anais... Americana: Consórcio PCJ, 2010.

RAMOS, Marilene. Gestão de recursos hídricos e cobrança pelo uso da água. Rio de Janeiro: Fundação Getulio Vargas — Ebap, p. 1-61, mar. 2007. 
ROMAN, Rodrigo; FOLEGATTI, Marcos; ORELLANA-GONZÁLEZ, Alba. Situação dos recursos hídricos nas bacias hidrográficas dos rios PCJ, utilizando um modelo desenvolvido em dinâmica de sistemas. Revista de Engenharia Agrícola, Jaboticabal, v. 29, n. 4, p. 578-590, out./dez. 2009.

SEROA DA MOTTA, Ronaldo. Economia ambiental. Rio de Janeiro: FGV, 2006.

SEROA da MOTTA, Ronaldo. O uso de instrumentos econômicos na gestão ambiental. Brasília: Ipea, 2000. Disponível em: <www.undp.org.cu/eventos/instruverdes/Instr\%20Econ\%20Gestion\%20 Ambiental\%20R\%20Seroa\%20da\%20Motta.pdf>. Acesso em: 1ํo set. 2011.

SILVA, Aneilson B.; GODOI, Christiane K.; BANDEIRA-DE-MELLO, Rodrigo. Pesquisa qualitativa em estudos organizacionais: paradigmas, estratégias e métodos. 2. ed. Rio de Janeiro: Saraiva, 2010.

SILVEIRA, Geraldo L.; GOLDENFRUM, Joel A. Taxa não é cobrança: uma proposta para efetiva aplicação do Instituto de Gestão dos Recursos hídricos para drenagem urbana. Revista Brasileira de Recursos Hídricos, Porto Alegre, v. 14, n. 4, p. 71-80, out./dez. 2009.

SINISGALLI, Paulo A. et al. Disposição a pagar pelo uso da água na bacia do rio Paraíba do Sul - trecho São Paulo, Brasil. In: JACOBI, Pedro R.; SINISGALLI, Paulo A. Governança da água na América Latina e Europa: atores sociais, conflitos e territorialidade. São Paulo: Annablume, 2009. v. 3, p. 11-35.

SOUZA JR., Wagner C. Gestão das águas no Brasil, reflexões, diagnósticos e desafios. São Paulo: IEB Instituto Internacional de Educação do Brasil, 2009.

VARELA, Carmen A. Instrumentos de políticas ambientais, casos de aplicação e seus impactos para as empresas e a sociedade. Revista Ciência e Administração, Fortaleza, v. 14, n. 2, p. 251-262, 2008.

VEETTIL, Prakashan C. et al. Complementarity between water pricing, water rights and local water governance. A Bayesian analysis of choice behavior of farmer in the Krishna river basin, Índia. Ecologial Economics, n. 70, p. 1756-1766, 2011.

Jacques Demajorovic é doutor em educação pela Universidade de São Paulo (USP) e professor do Programa de Pós-Graduação em Administração do Centro Universitário da FEI. É editor da Revista de Gestão Social e Ambiental. E-mail: jacquesd@fei.edu.br.

Carla Caruso é mestre em administração pelo Centro Universitário da FEI, doutoranda pelo Programa de Pós-Graduação em Educação da Universidade de São Paulo (USP), professora do Centro Paula Souza e Consultora em Sustentabilidade da Nike do Brasil. E-mail: carla.caruso@usp.br.

Pedro Roberto Jacobi é doutor em sociologia pela Universidade de São Paulo (USP), professor titular da Faculdade de Educação e do Programa de Pós-Graduação em Ciência Ambiental do Instituto de Energia e Ambiente (Procam/IEE/USP) da Universidade de São Paulo. É editor da Revista Ambiente e Sociedade. E-mail: prjacobi@gmail.com. 